\title{
Chemilly - Le Bourg
}

Philippe Arnaud

\section{OpenEdition \\ Journals}

Édition électronique

URL : http://journals.openedition.org/adlfi/5843

ISSN : 2114-0502

Éditeur

Ministère de la culture

Référence électronique

Philippe Arnaud, "Chemilly - Le Bourg », ADLFI. Archéologie de la France - Informations [En ligne], Auvergne, mis en ligne le 01 mars 2007, consulté le 27 avril 2019. URL : http://

journals.openedition.org/adlfi/5843

Ce document a été généré automatiquement le 27 avril 2019

(c) Ministère de la Culture et de la Communication, CNRS 


\title{
Chemilly - Le Bourg
}

\author{
Philippe Arnaud
}

Date de l'opération : 2007 (EX)

Inventeur(s) : Arnaud Philippe (INRAP)

La communauté d'agglomération de Moulins projetant d'enfouir un réseau sur $110 \mathrm{~m}$ aux abords de l'église paroissiale, six sondages ont été réalisés en juillet 2007. Le tracé traverse une place au nord-est et à l'est de l'église et suit une ruelle au sud. L'église SaintDenis est un édifice de style roman dont la date exacte de construction reste inconnue. On ne possède pas d'information sur un éventuel édifice antérieur.

Quoique distants de $16 \mathrm{~m}$, les deux sondages principaux du premier espace montrent que le mode d'inhumation des 19 sépultures découvertes présente des caractéristiques homogènes : emploi de coffres de bois non cloués pour les deux sépultures intégralement étudiées et d'un dispositif identique plausible pour les autres, absence d'épingles de linceul et de clous, absence de sarcophages et de coffres de pierres. Leur densité, relativement forte au chevet où il existe cependant des vides, est faible dans le sondage septentrional où les trois seules tombes sont très proches, et nulle au-delà dans le dernier sondage. Les rares recoupements (toujours en bordure de sépulture) attestent l'utilisation de marques de surface. On s'interroge sur l'éventuelle existence de regroupements, d'autant qu'adultes et enfants sont fréquemment juxtaposés. Dans le sondage nord, une sépulture d'immature semble même avoir été enfouie dans la fosse d'un adulte qu'elle surmonte directement. Le mode d'inhumation et l'arrêt des inhumations après recoupement des tombes du sondage nord par un fossé placent l'utilisation de cet espace funéraire entre la construction de l'église aux XI ${ }^{\mathrm{e}}-\mathrm{XII}{ }^{\mathrm{e}} \mathrm{s}$. et le XIII ${ }^{\mathrm{e}} \mathrm{s}$.

Orienté nord-sud, le fossé semble entériner une limite spatiale peu différente de celle du cimetière ; il a livré de la céramique du XIII ${ }^{\mathrm{e}} \mathrm{s}$. et un éperon en fer. Des sarcophages romans ont été découverts en 1994 devant la façade occidentale de l'église, ce qui suggère la coexistence de deux parties du cimetière caractérisées par des modes d'inhumation dominants différents (BSR 1994, p. 15, Sébastien Gaime). Les vestiges de la deuxième zone, au sud et au sud-est du sanctuaire, offrent le panorama classique du cimetière «basmédiéval »/moderne : forte densité, recoupements importants, présence de clous, emploi 
dominant de cercueils cloués, épingles de linceul, bois conservé... Neuf sépultures entaillant le substrat alluvial à faible profondeur y ont été repérées, dans deux sondages distants de $20 \mathrm{~m}$. Le sondage sud, implanté à $7 \mathrm{~m}$ du mur gouttereau, montre qu'une limite du cimetière, dont ne subsiste aucune trace physique, existait au droit du contrefort séparant les $2{ }^{\mathrm{e}}$ et $3{ }^{\mathrm{e}}$ travées. Les seuls vestiges mis au jour à l'est de cette limite, dans le $3{ }^{\mathrm{e}}$ sondage, sont ceux de deux fossés nord-est - sud-ouest, peut-être contemporains de celui de la première zone.

ARNAUD Philippe avec la collaboration de GATTO Esther (anthropologie), HORRY Alban (céramologie), BRIZARD Marcel (DAO) et CÉCILLON Christian (numismatique)

\section{INDEX}

Index géographique : Auvergne, Allier (03), Chemilly

Thèmes : adulte, céramique médiévale, cimetière paroissial, coffre en bois, église, enfant, fossé, inhumation, sarcophage, sépulture

Index chronologique : Moyen Âge, Temps Modernes, XIe siècle apr. J.-C., XIIe siècle apr. J.-C., XIIIe siècle apr. J.-C.

operation Expertise (EX)

\section{AUTEURS}

PHILIPPE ARNAUD

INRAP 